\title{
Chromium(VI) Adsorption Behavior of Silk Sericin Beads
}

\author{
Hyo Won Kwak ${ }^{a}$, Ye Sol Yang a , Moo Kon Kimª, Jeong Yun Lee ${ }^{a}$, Haesung Yun ${ }^{\mathrm{a}}$, Min Hwa Kimª \\ and Ki Hoon Lee $\mathrm{e}^{\mathrm{a}, \mathrm{b}, \mathrm{c} *}$ \\ ${ }^{a}$ Department of Biosystems \& Biomaterials Science and Engineering, Seoul National University, Seoul 151-921, Korea \\ ${ }^{b}$ Center for Food and Bioconvergence, Seoul National University, Seoul 151-921, Korea \\ ${ }^{c}$ Research Institute for Agriculture and Life Sciences, Seoul National University, Seoul 151-921, Korea
}

\section{Abstract}

Silk sericin (SS) has been fabricated into beads using a $1 \mathrm{M} \mathrm{LiCl/DMSO} \mathrm{solvent} \mathrm{and} \mathrm{utilized}$ as a heavy metal adsorbent. Among the various heavy metals, we targeted $\mathrm{Cr}(\mathrm{VI})$ for adsorption using SS beads and found that its adsorption depended on the coagulant used for the fabrication of the SS beads. When methanol was used as a coagulant, the beads had a better adsorption capacity than when ethanol was used except at $\mathrm{pH} 1$. The adsorption behavior of $\mathrm{Cr}(\mathrm{VI})$ on the SS beads followed the BET isotherm. The maximum adsorption capacity was $33.76 \mathrm{mg} / \mathrm{g}$ at $\mathrm{pH}$ 2. The adsorption of $\mathrm{Cr}(\mathrm{VI})$ was confirmed by FT-IR and EDS analyses. Finally, the desorption was carried out using $\mathrm{NaOH}$ solution, and it was found that $73.19 \%$ of the adsorbed $\mathrm{Cr}(\mathrm{VI})$ could be detached.

(C) 2013 The Korean Society of Sericultural Sciences

Int. J. Indust. Entomol. 26(1), 47-53 (2013)
Received : Accepted :

5 March 2013

19 March 2013

\section{Keywords:}

Silk sericin, Heavy metal adsorbent, Bioadsorption,

Waste water treatment

\section{Introduction}

The recovery and utilization of silk sericin (SS) have attracted much interest among scientists in the field of sericulture, since they can provide an additional benefit to the sericulture industry. SS can be recovered from degumming waste using membrane techniques (Capar et al., 2004). However, without an appropriate application of the recovered SS, this technique will not be applied in the industry. Therefore, there has been much research on new applications of SS besides in cosmetics, where SS has been used widely for a long time. We have previously reported that SS can be fabricated into beads (Oh et al., 2007) and microspheres (Oh et al., 2011) using a 1 $\mathrm{M} \mathrm{LiCl} / \mathrm{DMSO}$ solvent. As one potential application, the SS beads and microspheres were used as drug carriers. However, there has been some debate on the safety of SS biomaterials, and there have been several reports questioning the biocompatibility of SS (Liu et al., 2006; B. Panilaitis et al., 2003). Although the use of SS in the biomedical field is attractive and many studies have been reported on such applications (Kundu et al., 2008; Kim et al., 2012; Seo et al., 2011), they cannot be realized in the near future unless these safety concerns are solved. Outside the

\section{*Correspondence :}

Ki Hoon Lee

Department of Biosystems \& Biomaterials Science and Engineering, Seoul National University

1 Gwanak-ro, Gwanak-gu, Seoul 151-921, Korea

Tel: +82-2-880-4625 / FAX: +82-2-873-2285

E-mail: prolee@snu.ac.kra

http://dx.doi.org/10.7852/ijie.2013.26.1.047

(C) 2013 The Korean Society of Sericultural Sciences 
biomedical field, there have been attempts to use SS in materials fields as fibers (Zhang et al., 2012; Oh et al., 2008) and films (Teramoto et al., 2005). However, the pure SS and various polymer blends with SS could not achieve the mechanical strength needed for practical applications. Therefore, more effort is required to find an appropriate application of SS.

Heavy metal pollution is a serious problem that has a severe impact on the environment and human health. Lead, cadmium, mercury and chromium are the major toxic heavy metals, and their levels in any human commodities are strictly regulated by the government. Among these toxic metal ions, we focused on the removal of chromium using SS. Chromium and its compounds are widely used in various industrial processes such as tanning, electroplating, and synthesis of dyes and pigments. Chromium can exist in eleven valence states, but $\mathrm{Cr}(\mathrm{III})$ and $\mathrm{Cr}(\mathrm{VI})$ have the largest impact on the environment because of their stability (Kotaś et al., 2000). $\mathrm{Cr}(\mathrm{VI})$ has a higher toxicity than $\mathrm{Cr}(\mathrm{III})$ because of its high uptake by cells and the formation of radicals inside the cell (Costa, 2003). Therefore, there have been many studies on the removal of $\mathrm{Cr}(\mathrm{VI})$, and various materials and techniques have been applied (Owlad et al., 2009). Conventionally, the precipitation technique has been widely used for $\mathrm{Cr}(\mathrm{VI})$ removal, but the disposal of the solid waste remains a problem. Adsorption techniques have been widely used recently, where activated carbon is used as an adsorbent. However, because of the high cost of the activated carbon, there is a need to find cheaper alternatives. Various agricultural by-products have been investigated as substitutes, and many were found be effective for the removal of $\mathrm{Cr}(\mathrm{VI})$ (Sud et al., 2008). Mudhoo et al. (Mudhoo et al., 2012) suggested that the biomass for the metal adsorption should come in large quantities from industrial wastes. SS meets these requirements, and previously, Song et al. (Song et al., 2007) has reported on Cr(III) adsorption using SS. They prepared amphiphilic core-shell poly(methyl acrylate)/SS nanospheres, and found that $4.876 \mathrm{mg}$ of $\mathrm{Cr}$ (III) can be adsorbed per gram of nanospheres.
In this study, we have prepared SS macrobeads using a previously reported method (Oh et al., 2007) and investigated their $\mathrm{Cr}(\mathrm{VI})$ adsorption ability. The removal of $\mathrm{Cr}(\mathrm{VI})$ was measured using colorimetric methods, and the adsorption of $\mathrm{Cr}(\mathrm{VI})$ was confirmed by FT-IR and EDS analyses. In addition, we predicted the mechanism of adsorption of $\mathrm{Cr}(\mathrm{VI})$ onto SS using isothermal models.

\section{Materials and Methods}

\section{Materials}

Silkworm cocoons were kindly provided by Heung Jin Co. Ltd. All chemicals were purchased from Sigma-Aldrich (USA).

\section{Extraction of silk sericin}

SS was extracted by boiling $25 \mathrm{~g}$ of Bombyx mori silkworm cocoons with $1 \mathrm{~L}$ of distilled water using an autoclave for $1 \mathrm{~h}$ at $120^{\circ} \mathrm{C}$. The extracted solution was filtered with a nonwoven filter in order to remove the remaining cocoons. The SS solution was frozen at $-70^{\circ} \mathrm{C}$ for $4 \mathrm{~h}$ and lyophilized.

\section{Preparation of silk sericin beads}

The lyophilized SS was dissolved in $1 \mathrm{M} \mathrm{LiCl} /$ DMSO solution for $2 \mathrm{~h}$ at $50^{\circ} \mathrm{C}$ to prepare a dope solution of $25 \%(\mathrm{w} / \mathrm{v})$. The dope solution was dropped into alcohol coagulants through a $26 \mathrm{G}$ syringe using a syringe pump (KD scientific, USA). Methanol and ethanol were used as coagulants, and the obtained beads are designated as SS-M and SS-E, respectively. The SS beads were left in the coagulant bath for another $1 \mathrm{~h}$. They were then filtered with a nonwoven filter and washed with the same coagulant to remove the residual $\mathrm{LiCl}$ and DMSO. To enhance the water stability and mechanical strength of the SS beads, the beads were immersed in a crosslinking reagent. The crosslinking was performed with $2 \%$ 
(v/v) glutaraldehyde (GA) in the same coagulant. The reaction was carried out for $1 \mathrm{~h}$ at room temperature. Finally, the SS beads were washed with the same coagulant followed by distilled water to remove the excess GA.

\section{Batch adsorption and desorption studies}

The stock solution of $\mathrm{Cr}(\mathrm{VI})(1000 \mathrm{mg} / \mathrm{L})$ was prepared by dissolving $2.827 \mathrm{~g}$ of potassium dichromate, $\mathrm{K}_{2} \mathrm{Cr}_{2} \mathrm{O}_{7}$, in $1 \mathrm{~L}$ of distilled water. Different concentrations of $\mathrm{Cr}(\mathrm{VI})$ solution were prepared by diluting the stock solution with distilled water. Each adsorption experiment was conducted in a $250 \mathrm{~mL}$ Erlenmeyer flask containing 100 $\mathrm{mL}$ of $\mathrm{Cr}(\mathrm{VI})$ solution. The mixtures were stirred continuously on a multi-stirrer (JEIO TECH, Korea) at $180 \mathrm{rpm}$ for $24 \mathrm{~h}$ at $25^{\circ} \mathrm{C}$. In order to find the optimum $\mathrm{pH}$, batch adsorption experiments were conducted in a $\mathrm{pH}$ range from 1.0 to 5.0 for the $\mathrm{Cr}(\mathrm{VI})$ solution $(100 \mathrm{mg} / \mathrm{L})$. The adsorption isotherm was studied by varying the initial $\mathrm{Cr}(\mathrm{VI})$ concentrations from 25 to $300 \mathrm{mg} / \mathrm{L}$. The concentration of $\mathrm{Cr}(\mathrm{VI})$ in the solution was determined using a standard colorimetric method (Snell et al., 1959). After each batch experiment, the $\mathrm{Cr}(\mathrm{VI})$ solution was filtered with a nonwoven to remove SS beads and reacted with 1,5-diphenylcarbazide in acid solution. The formation of a red-violet complex measured spectrophotometrically at $540 \mathrm{~nm}$ using microplate reader (Synergy H1, Biotek, USA). The equilibrium adsorption capacity, $q_{e}$, was determined using the following equation:

$$
q_{e}=\frac{\left(C_{0}-C_{\mathrm{e}}\right)}{M} \times V
$$

where $C_{o}$ and $C_{e}$ are the initial and the equilibrium concentration of the $\mathrm{Cr}(\mathrm{VI})$ in the testing solution (mg/ $\mathrm{L}), \mathrm{V}$ is the volume of the testing solution (L), and $\mathrm{M}$ is the weight of the SS beads (g).

The desorption of $\mathrm{Cr}(\mathrm{VI})$ was performed by using $0.1 \mathrm{M} \mathrm{NaOH}$ solution. After the adsorption experiment, the SS beads were recovered from the
$\mathrm{Cr}(\mathrm{VI})$ solution and washed gently with distilled water three times to remove the residual $\mathrm{Cr}(\mathrm{VI})$ on the surface. The beads were immersed into $100 \mathrm{~mL}$ of $0.1 \mathrm{M} \mathrm{NaOH}$ and stirred overnight. The desorption efficiency was calculated as

$$
\begin{aligned}
& \text { esorption efficiency }(\%)= \\
& \frac{\text { Mass of } C r(V I) \text { ions desorbed }}{\text { Mass of } C r(V I) \text { ions adsorbed }} \times 100
\end{aligned}
$$

\section{Characterization of sericin beads}

ATR-FTIR spectroscopy (Thermo Scientific, USA) was used to identify the $\mathrm{Cr}(\mathrm{VI})$ adsorbed onto the SS beads. The samples were examined within the wavenumber range $700-4000 \mathrm{~cm}^{-1}$, and 32 scans with $8 \mathrm{~cm}^{-1}$ resolution were used to obtain the spectra. The morphology and EDS spectra of the SS beads were evaluated using a field-emission scanning electron microscope (FE-SEM) (SUPRA 55VP, Carl Zeiss, Germany).

\section{Results and Discussion}

\section{Evidence of $\mathrm{Cr}(\mathrm{VI})$ adsorption onto SS beads}

We prepared SS beads following the same procedure reported previously by our group (Oh et al., 2007). For their application as a bioadsorbent, a further crosslinking procedure using glutaraldehyde is employed in order to make the beads insoluble. Fig. 1a shows an SEM image of an SS bead after Cr(VI) adsorption. The bead maintained its shape even after it was subjected to $\mathrm{pH} 2$. EDS analysis of the surface of an SS bead after Cr(VI) adsorption revealed that $\mathrm{Cr}(\mathrm{VI})$ is deposited on its surface (Fig. 1b). Besides those for carbon, nitrogen, and oxygen, two peaks for chromium could be observed. Fig. 2 shows the ATR-FTIR spectra of the SS bead before and after $\mathrm{Cr}(\mathrm{VI})$ adsorption. After $\mathrm{Cr}(\mathrm{VI})$ adsorption, new peaks due to $\mathrm{Cr}(\mathrm{VI})-\mathrm{O}$ stretching vibration could be found at 897 and $933 \mathrm{~cm}^{-1}$ (Bolte et al., 2005). This 


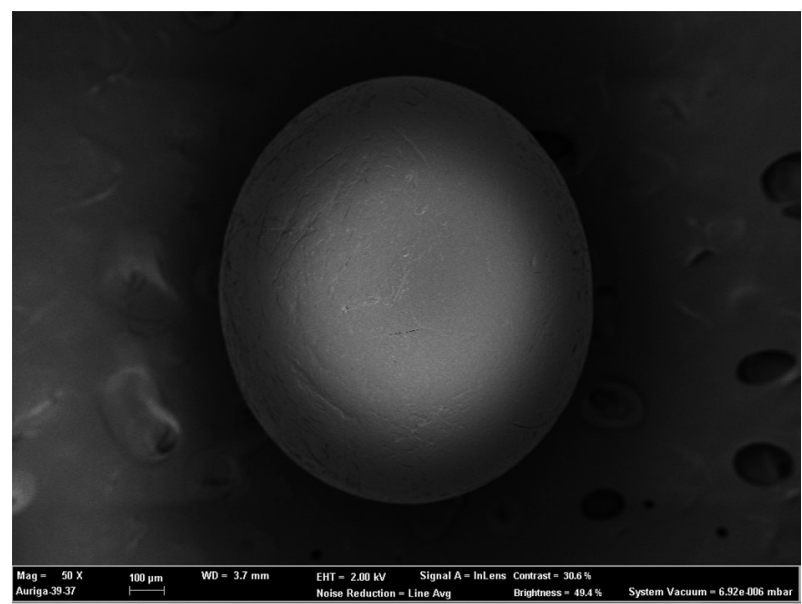

(a)

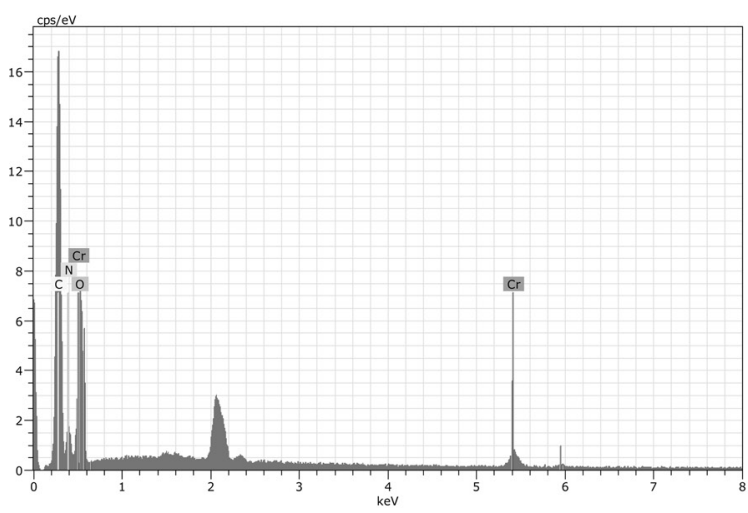

(b)

Fig. 1. SEM image of an SS bead (a) and EDS analysis of the surface of the SS bead (b).

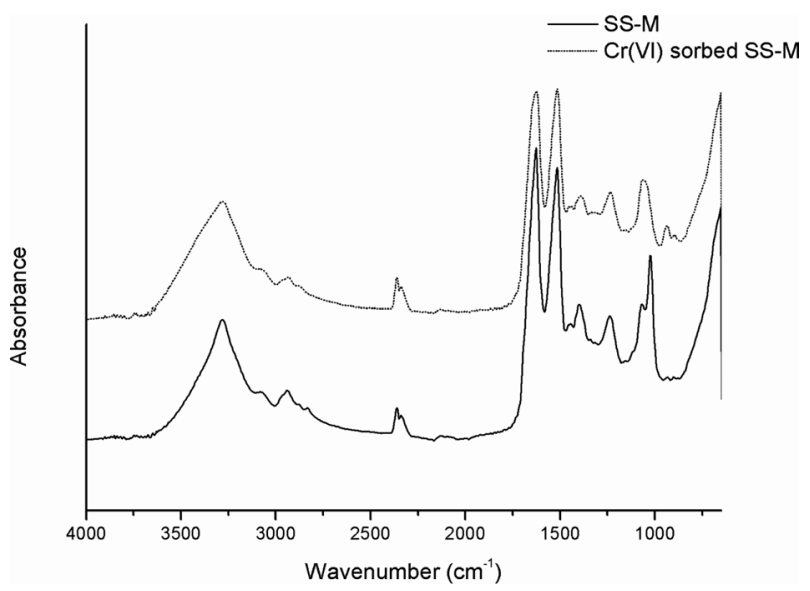

Fig. 2. ATR-FTIR spectra of SS beads before and after $\mathrm{Cr}(\mathrm{VI})$ adsorption.

also demonstrates that $\mathrm{Cr}(\mathrm{VI})$ is adsorbed on the $\mathrm{SS}$ bead. There have been some reports that metal ions

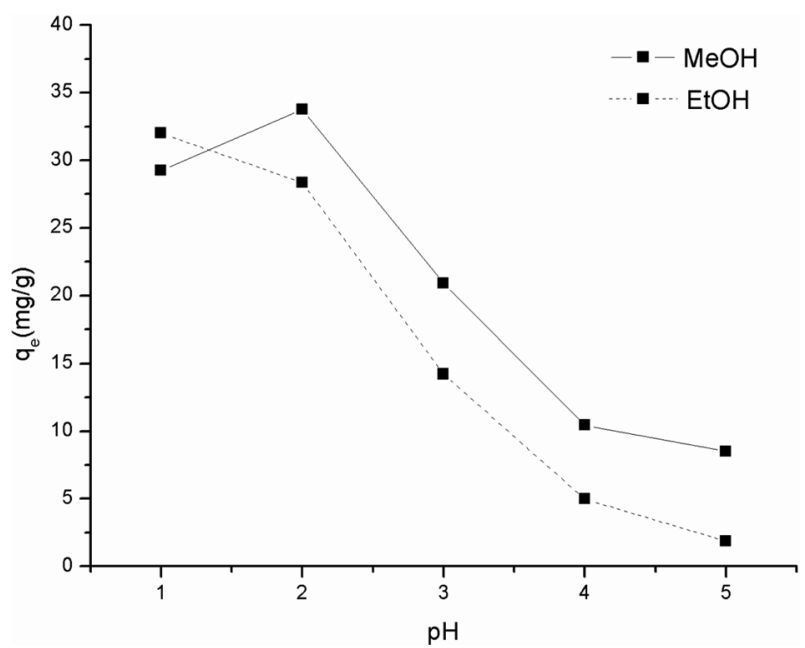

Fig. 3. Effect of coagulant and $\mathrm{pH}$ on the adsorption of $\mathrm{Cr}(\mathrm{VI})$ onto SS beads.

can induce structural deformation of proteins (Zhou et al., 2004; Ahern and Garrell, 1991). However, there was no change in the amide I (1600-1700 $\left.\mathrm{cm}^{-1}\right)$ peak after $\mathrm{Cr}(\mathrm{VI})$ adsorption, indicating that there were no structural changes. With these results, we confirm that $\mathrm{SS}$ beads can be used as a bioadsorbent of $\mathrm{Cr}(\mathrm{VI})$.

\section{Effect of coagulant and $\mathrm{pH}$ on $\mathrm{Cr}(\mathrm{VI})$ adsorption}

The SS beads were prepared by adding the dope solution dropwise into a coagulant. We have previously shown that both methanol and ethanol can be used as coagulants (Oh et al., 2007). Fig. 3 shows the effect of the coagulant and the $\mathrm{pH}$ on the $\mathrm{Cr}(\mathrm{VI})$ adsorption. Overall, SS beads prepared with the methanol coagulant (SS-M) had better adsorption capacities than those prepared with the ethanol coagulant (SS-E), except at $\mathrm{pH} 1$. The adsorption of $\mathrm{Cr}(\mathrm{VI})$ is poorer at higher $\mathrm{pH}$ in both SS-M and SS-E. It is well known that $\mathrm{Cr}(\mathrm{VI})$ exists as a chromate ion in solution, and its exact chemical formula depends on the $\mathrm{pH}$. Above $\mathrm{pH} 6, \mathrm{Cr}(\mathrm{VI})$ forms $\mathrm{CrO}_{4}{ }^{2-}$; between $\mathrm{pH} 2$ and 6, it forms $\mathrm{HCrO}_{4}^{-}$and $\mathrm{Cr}_{2} \mathrm{O}_{7}{ }^{2-}$; and below $\mathrm{pH} 1, \mathrm{H}_{2} \mathrm{CrO}_{4}$ is predominant. Because of this ionic character, $\mathrm{Cr}(\mathrm{VI})$ is adsorbed onto positive surfaces instead of negative surfaces. SS has a high portion of charged amino acids compared to silk fibroin, and 
negatively charged amino acids are more predominant than positively charged ones. For this reason, the isoelectric point (pI) of SS is slightly acidic, between 4 and 5. This means that the net charge of SS below $\mathrm{pH} 4$ is positive, whereas it is negative when the $\mathrm{pH}$ is higher than 5. Therefore, chromate anions could not be adsorbed at high $\mathrm{pH}$ because of the charge repulsion. The maximum adsorption occurred at $\mathrm{pH} 2$ for SS-M and at $\mathrm{pH} 1$ for SS-E. Interestingly, SS-M had a better adsorption capacity than SS-E. This might be due to the slight differences between the hydrophobicities of the coagulants. When the SS solution is dripped into the coagulant, mass transfer occurs between the solvent (1 M LiCl/DMSO) and the coagulant (methanol or ethanol). In particular, the solvent diffuses out and the coagulant diffuses in, which results in solidification of the SS. During this event, SS will come into contact with the coagulant, and its surface characteristics will depend on the hydrophobicity or hydrophilicity of the coagulant. If the coagulant is hydrophobic, then the hydrophobic domain of the SS will face toward the surface of the bead. In the opposite case, where the coagulant is hydrophilic, now the hydrophilic domain of SS will be located on the surface of the bead. Because methanol is more hydrophilic than ethanol, the surface of the SS-M would be more hydrophilic than that of the SS-E. In general, charged amino acids make up the hydrophilic domains of proteins. Therefore, there will be more charged amino acids on the surfaces of the SS-M beads than on the SS-E surfaces, which will result in higher adsorption capacities in all $\mathrm{pH}$ ranges. Since SS-M has a better adsorption capacity for $\mathrm{Cr}(\mathrm{VI})$ and shows the highest adsorption capacity at $\mathrm{pH}$ 2, SS-M was used as the adsorbent and the $\mathrm{pH}$ of the testing $\mathrm{Cr}(\mathrm{VI})$ solution was fixed at 2 for further experiments.

\section{Effect of initial concentration of $\mathrm{Cr}(\mathrm{Vl})$}

The initial concentration of $\mathrm{Cr}(\mathrm{VI}), C_{0}$, is important, since it is the driving force for the $\mathrm{Cr}(\mathrm{VI})$ adsorption. As shown in Fig. 4, for $C_{0}$ values up to $100 \mathrm{mg}$ / $\mathrm{L}$, the equilibrium adsorption capacity, $q_{e}$, increases

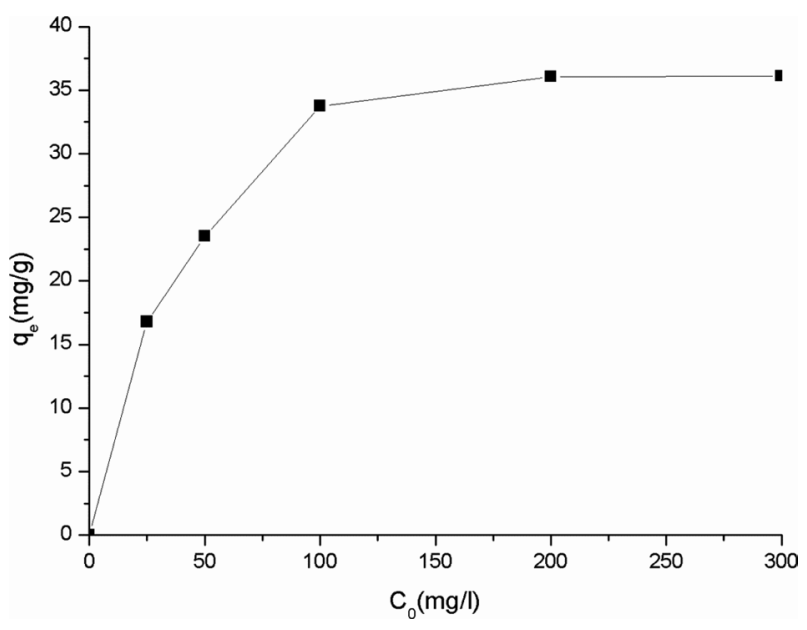

Fig. 4. Effect of initial concentration of $\mathrm{Cr}(\mathrm{VI})$ on the adsorption capacity of SS beads.

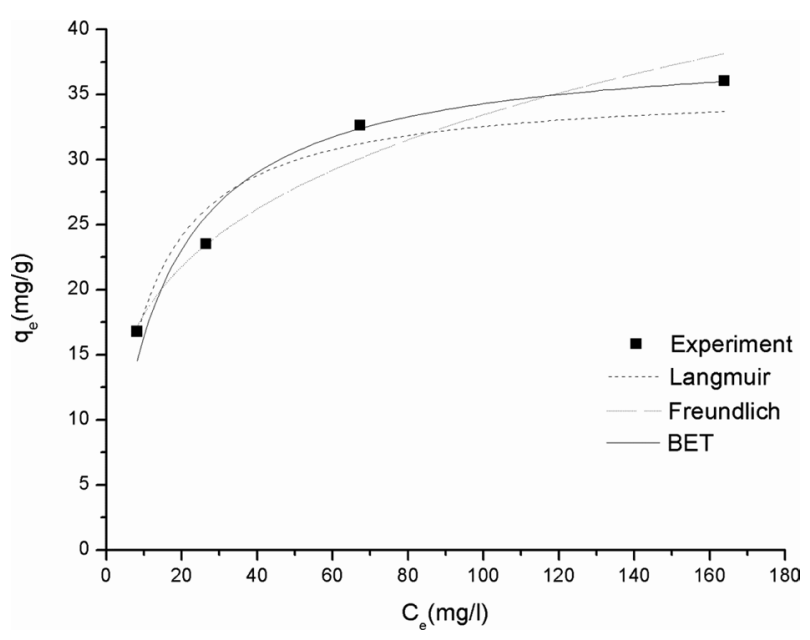

Fig. 5. Adsorption isotherm for $\mathrm{Cr}(\mathrm{VI})$ onto SS beads.

almost linearly. The $q_{e}$ is $16.78 \mathrm{mg} / \mathrm{g}$ at $C_{0}=25 \mathrm{mg} / \mathrm{L}$ but increases to $33.76 \mathrm{mg} / \mathrm{g}$ at $C_{0}=100 \mathrm{mg} / \mathrm{L}$. When $C_{0}$ exceeds $200 \mathrm{mg} / \mathrm{L}, q_{e}$ plateaus at about $36 \mathrm{mg} / \mathrm{g}$, indicating saturation. Since the SS beads have only a limited number of binding sites, a higher concentration gradient is required in order to achieve saturation. This means that the removal ratio will decrease with increasing $C_{0}$, as was observed in this experiment.

\section{Adsorption isotherm}

The adsorption isotherm provides useful information about what kind of interaction occurs between 
Table 1. Isotherm model constants

\begin{tabular}{|c|c|c|c|c|c|c|c|c|c|}
\hline \multirow{2}{*}{$\begin{array}{c}\text { Isotherm } \\
\text { models }\end{array}$} & \multicolumn{4}{|c|}{ Langmuir isotherm } & \multicolumn{3}{c|}{ Freundlich isotherm } & \multicolumn{4}{c|}{ BET isotherm } \\
\cline { 2 - 10 } & $Q$ & $b$ & $R^{2}$ & $K$ & $n$ & $R^{2}$ & $Q$ & $B$ & $R^{2}$ \\
\hline Constants & 35.68 & 0.10 & 0.938 & 9.81 & 3.75 & 0.957 & 39.0 & $8.90 \times 10^{5}$ & 0.997 \\
\hline
\end{tabular}

the metal ion and the adsorbent. Fig. 5 shows the adsorption isotherm for $\mathrm{Cr}(\mathrm{VI})$ adsorption onto SS$\mathrm{M}$, and Table 1 shows the Langmuir, Freundlich, and BET model constants. It was found that the BET model fits better than the Langmuir or Freundlich model. The differences between these models are that the Langmuir model assumes monolayer adsorption while the Freundlich and BET models assume multilayer adsorption. As shown in Table 1, the Langmuir model has the least $R^{2}$ value, indicating that the $\mathrm{Cr}(\mathrm{VI})$ adsorption onto SS-M occurs on multiple layers rather than one single layer. This is obvious, because although the SS bead has a compact inner structure, chromate ions can penetrate into the interior part of the SS beads because of swelling of the SS or the concentration gradient. Therefore, once the outermost layer of the SS adsorbs $\mathrm{Cr}(\mathrm{VI})$, the next layer will be ready for additional $\mathrm{Cr}(\mathrm{VI})$ adsorption. As a result, the Langmuir model is inadequate for explaining the results of this study. On the other hand, the Freundlich model assumes that the multilayers are heterogeneous, whereas the BET model is an extension of Langmuir model, in which each layer behaves according to the Langmuir model. Thus, the Freundlich model is also incapable of explaining the mechanism of $\mathrm{Cr}(\mathrm{VI})$ adsorption onto SS, because the affinity of $\mathrm{Cr}(\mathrm{VI})$ would be the same for all SS layers. The mechanism of $\mathrm{Cr}(\mathrm{VI})$ adsorption onto SS can therefore be explained as follows. At first, $\mathrm{Cr}$ (VI) is adsorbed onto the outermost layer of the SS bead, where the positively charged amino acids act as the binding sites for chromate anions. Once the outermost layer is fully occupied, the $\mathrm{Cr}(\mathrm{VI})$ will be adsorbed onto the next layer, and this process will be repeated until all accessible layers are saturated.
Table 2. Desorption efficiency for Cr(VI) from SS beads

\begin{tabular}{|c|c|c|}
\hline \multicolumn{2}{|c|}{$\begin{array}{c}\text { Mass of Cr(VI) in SS-M (mg) } \\
\text { Washing }\end{array}$} & $\begin{array}{c}\text { Cr(VI) } \\
\text { desorption } \\
\text { efficiency (\%) }\end{array}$ \\
\hline 33.76 & 9.05 & 73.19 \\
\hline
\end{tabular}

\section{Removal of $\mathrm{Cr}(\mathrm{VI})$}

For reuse of the SS beads, the adsorbed Cr(VI) should be easily detached. There are many mechanisms for adsorption of $\mathrm{Cr}(\mathrm{VI})$ onto biosorbents. However, the fundamental adsorption mechanism is that the biosorbent should have positive charges in order to hold the negative chromate ions. As mentioned above, $\mathrm{SS}$ is a protein that has positive net charge at $\mathrm{pH} 2$. If we increase the $\mathrm{pH}$ of the solution then the SS would have a negative net charge, resulting in desorption of the chromate ions. Therefore, we washed the $\mathrm{Cr}(\mathrm{VI})$-adsorbed SS beads with $\mathrm{NaOH}$ solution. Table 2 shows the desorption results after $\mathrm{NaOH}$ washing. About $73.19 \%$ of the adsorbed $\mathrm{Cr}(\mathrm{VI})$ can be desorbed from the SS beads, which indicates that the SS beads can be continuously reused for $\mathrm{Cr}(\mathrm{VI})$ adsorption.

\section{Acknowledgment}

This work was supported by the Marine Biomaterials Research Center grant from Marine Biotechnology Program funded by the Ministry of Land, Transport and Maritime Affairs, Korea. 


\section{Reference}

Ahern. AM, Garrell RL (1991) Protein-metal interactions in protein-colloid conjugates probed by surface-enhanced Raman spectroscopy. Langmuir 7, 254-261.

Bolte M, Israeli Y, Djouani F, Rivaton A, Frezet L, Lessard RA (2005) Hologram formation reconsidered in dichromated polyvinylalcohol: polymer cross-linking around chromium (V) 195-204.

Capar G, Aygun SS, Gecit MR (2008). Treatment of silk production wastewaters by membrane processes for sericin recovery. Journal of Membrane Science 325, 920931.

Costa M (2003) Potential hazards of hexavalent chromate in our drinking water. Toxicology and Applied Pharmacology 188, 1-5.

Kim MK, Kwak HW, Lee JY, Yun H, Kim MH, Lee KH (2012) Effect of Lyoprotectant on the Solubility and Structure of Silk Sericin. Int J Indust Entomol 24, 133137

Kotaś J, Stasicka Z (2000) Chromium occurrence in the environment and methods of its speciation. Environmental Pollution 107, 263-283.

Kundu SC, Dash BC, Dash R, Kaplan DL (2008) Natural protective glue protein, sericin bioengineered by silkworms: Potential for biomedical and biotechnological applications. Prog Polym Sci 33, 998-1012.

Liu H, Ge Z, Wang Y, Toh SL, Sutthikhum V, Goh JCH (2007) Modification of sericin-free silk fibers for ligament tissue engineering application. J. Biomed. Mater. Res. Part B 82B, 129-138.

Mudhoo A, Garg VK, Wang S (2012) Removal of heavy metals by biosorption. Environ Chem Lett 10, 109-117.

Oh H, Lee JY, Kim A, Ki CS, Kim JW, Park YH, Lee KH (2007) Preparation of silk sericin beads using LiCl/ DMSO solvent and their potential as a drug carrier for oral administration. Fiber Polym 8, 470-476.

Oh H, Lee JY, Lee YK, Lee KH (2007) Enhanced Mechanical Property of Silk Sericin Beads Prepared from Ethanol-precipitated Sericin. 15, 171-174
Oh H, Lee JY, Kim A, Lee KH, Shin BS (2008) Preparation of PVA/Silk Sericin Blend Fiber Using LiCl/ DMSO Solvent. Text Sci Eng 48, 252-257

Oh H, Kim MK, Lee KH, (2011). Preparation of sericin microparticles by electrohydrodynamic spraying and their application in drug delivery. Macromol Res 19, 266-272.

Owlad M, Aroua MK, Daud WAW, Baroutian S (2009) Removal of Hexavalent Chromium-Contaminated Water and Wastewater: A Review. Water Air Soil Pollut 200, 59-77.

Panilaitis B, Altman GH, Chen J, Jin HJ, Karageorgiou V, Kaplan DL (2003). Macrophage responses to silk. Biomaterials 24, 3079-3085.

Seo CW, Um IC, Rico CW, Kang MY, (2011) Antioxidative and Hypoglycemic Effects of Silk Fibroin/ SericinMixtures in High Fat-Fed Mice. Int J Indust Entomol 23. 115-112

Snell FD, Snell CT (1959) Colorimetric methods of analysis, $2,3^{\text {rd }}$ ed. Van Nostrand company, Canada

Song Y, Jin Y, Sun J, Wei D (2007) Removal of trivalent chromium from aqueous solutions by amphiphilic coreshell poly(methyl acrylate)/silk sericin nanospheres. Polimery 52, 880-884.

Sud D., Mahajan G, Kaur MP (2008) Agricultural waste material as potential adsorbent for sequestering heavy metal ions from aqueous solutions - A review. Bioresource Technology 99, 6017-6027.

Teramoto H, Miyazawa M (2005) Molecular orientation behavior of silk sericin film as revealed by ATR infrared spectroscopy. Biomacromolecules 6, 2049-2057.

Zhang X, Khan MMR, Yamamoto T, Tsukada M, Morikawa H (2012) Fabrication of silk sericin nanofibers from a silk sericin-hope cocoon with electrospinning method. Int J Biol Macromol 50, 337-347

Zhou P, Xie X, Knight DP, Zong XH, Deng F, Yao WH (2004) Effects of $\mathrm{pH}$ and Calcium Ions on the Conformational Transitions in Silk Fibroin Using 2D Raman Correlation Spectroscopy and 13C Solid-State NMR. Biochemistry 43, 11302-11311. 